\title{
Morfofonêmica, Nasalidade e Redução Silábica em Bakairi (Karib Sul)
}

\author{
Morphophonemics, Nasality and Silábic Reduction in Bakairi (South Karib)
}

\author{
Rodrigo Pereira da Silva Rosa \\ Universidade Federal do Rio de Janeiro (UFRJ) \\ Evandro de Sousa Bonfim \\ Museu Nacional (MN) \\ Universidade Federal do Rio de Janeiro (UFRJ)
}

Resumo. A partir da leitura e análise de textos e dados da língua Bakairi, o trabalho tem como objetivo mostrar aspectos da deriva histórica da fonologia e morfologia do Bakairi (do ramo Karib Sul). O foco analítico está no processo de redução silábica do Kurâ Itanro, privilegiando o contexto da morfofonêmica da língua. O processo de redução silábica do Bakairi produz variados fenômenos linguísticos de ordem fonológica, prosódica, morfológica e sintática. Tal processo, na língua Bakairi, diferencia-se das demais línguas da família Karib, ficando a nasalidade como importante traço para se recuperar os processos de redução silábica, tanto os que evidenciam a queda das consoantes nasais, produzindo sílabas com rima de núcleo ramificado, como a emergência da nasalidade morfológica, referentes a índices de pessoa e sufixos nominais.

Palavras-Chave: Morfofonêmica; Nasalidade; Sílaba; Bakairi.

Abstract: Based on the reading and analysis of texts and data of the Bakairi language, this paper intends to show aspects of the historical drift of Bakairi's phonology and morphology (from the South Karib branch). The analytical focus is on the process of syllabic reduction of Kurâ Itanro, privileging the context of the morphophonemic language. The process of syllable reduction of Bakairi generates several linguistics phenomena of phonological, prosodic, morphological, and syntactic order. This process, in the Bakairi language, differs from the other languages of the Karib family, with nasality as an important trait to recover the syllabic reduction processes, both those that show the fall of nasal consonants, producing syllables with rhyme of branched nucleus and the appearance of morphological nasality, referring to person indexes and nominal suffixes.

Keywords: Morphophonemic; Nasality; Syllabe; Bakairi.

\section{Introdução}

A redução silábica na Família Karib combina e produz variados fenômenos linguísticos de ordem fonológica, prosódica, morfológica e sintática. Padrões explicativos, bem como os principais contextos de ocorrência da redução silábica na família linguística ameríndia, vêm sendo propostos por autores como Gildea (1995) e Mattei-Müller (1981), baseados, sobretudo, nas línguas faladas ao Norte da América do Sul. Assim, dados provenientes de línguas meridionais do agrupamento linguístico mostram-se importantes para ampliação da discussão sobre o papel da redução silábica na variação diacrônica dos idiomas Karib, bem como dos intentos de classificação interna.

O artigo tem como objetivo mostrar os principais resultados da redução silábica em Bakairi que, ao contrário das demais línguas Karib, não incide sobre as vogais produzindo, por exemplo, coda 
silábica, mas antes sobre consoantes homorgânicas que deixam como traço a nasalidade que institui na língua tanto vogais nasalizadas sem estatuto fonêmico bem como morfemas gramaticais que infrassegmentais. O texto combina reflexões e dados de trabalhos consolidados sobre o Bakairi, como o de Tania Clemente de Souza $(1995,1999,2006)$, com estudos mais recentes sobre o fenômeno da redução silábica na língua (ROSA, 2017), que contam com dados primários coletados na Terra Indígena Bakairi em 2013 e pesquisas posteriores com falantes da língua (BONFIM, 2018).

O texto mostra primeiramente o povo Bakairi e os estudos sobre a língua falada por eles, o Kurâ Itanro (língua de gente), que se destaca por trabalhos históricos que combinam linguística e etnologia, a saber, as pesquisas de Karl Von den Steinen e Capistrano de Abreu, bem como os desenvolvimentos recentes que enfocam a fonologia, a sintaxe e a análise do discurso de narrativas mitológicas e históricas que compõem a extensa e rica obra de Souza (1995). O trabalho se insere assim na descrição formal da morfologia da língua, apresentando elementos da redução silábica atuando na diacronia e sem interferência dos processos de afixação como nas demais línguas Karib, apresentando os resultados da queda das consoantes: o surgimento de vogais cuja nasalidade pode ser interpretada como fonológica não-contrastiva ou como morfofonêmica.

\section{Povo e Língua Bakairi}

A população Bakairi, composta de 1.100 indivíduos, segundo dados da Funai (2013), está distribuída em duas terras indígenas, Santana e Bakairi, localizadas respectivamente nos municípios de Nobres e Paranatinga, no estado de Mato Grosso, Centro-Oeste do Brasil. Os Bakairi se dispersaram a partir do lugar que consideram como berço mítico de origem se dividindo em dois grupos, mais tarde conhecidos como "mansos" ou "ocidentais", absorvidos como mão-de-obra pela sociedade colonial desde o século XVIII, e os "brabos" ou "orientais", que se isolaram no Alto Xingu.

As duas faç̧ões Bakairi retomaram o contato a partir das expedições de Karl Von den Steinen no final do século XIX (1884 e 1887), evento considerado marcante para os Bakairi, tanto em termos de reorganização interna como de divulgação nacional e internacional do grupo. Em 1920 foi criada pelo Serviço de Proteção ao Índio (SPI) a Área Indígena Bakairi, para onde migraram os indígenas, inclusive os xinguanos, fugindo de maus tratos impostos por fazendeiros. Ao longo do século XX, os Bakairi resistiram à incorporação da população como mão de obra das fazendas de gado e das proibições em torno do uso da língua e de costumes tradicionais promovidos pelos órgãos de tutela e a ação missionária.

As pesquisas sobre a língua Bakairi têm como característica o forte componente etnográfico. Desde os relatos sobre as viagens exploratórias às cabeceiras do Xingu realizadas em 1887 e 1888, Karl Von den Steinen procura estabelecer relações entre fatos linguísticos (a filiação do Bakairi à Família Karib, a ocorrência de determinados vocábulos, a composição do léxico mitológico) e fatos etnológicos, como a direção da dispersão dos povos Karib, hipóteses sobre o grau de contato com a sociedade ocidental a partir de cultivos como a banana e a interação com outros grupos linguísticos como o Arawak. Em Bakairi-Sprachen, a concepção de Gramática do autor germânico incluía o registro na língua nativa de vocabulário sobre fauna, flora, partes do corpo, instituições sociais e personagens míticos, além da glosa e comentários sobre narrativas mitológicas completas do grupo.

Movimento similar faz Capistrano de Abreu. A análise do autor brasileiro se situa no momento anterior 
à constituição da etnologia moderna, quando se considerava a descrição linguística como parte integrante da escrita etnográfica. Tal movimento discursivo também se fazia em contraposição ao estilo de trabalho dos viajantes estrangeiros na América do Sul, caracterizada pela coleta de listas de palavras e o impressionismo. Capistrano de Abreu chamava o trabalho que fazia de "selvagem" por se fundamentar na transcrição de depoimentos, sobretudo de narrativas mitológicas, ditados pelos próprios indígenas em língua nativa, acompanhadas de tradução interlinear, como tentativa de evitar a interferência da cultura e da língua do analista no material coletado. Tal procedimento, conhecido como fraseologia, teve grande repercussão nos estudos das línguas indígenas norte-americanas através de figuras como Franz Boas e Edward Sapir, ficando por ser coberto o papel do modelo na descrição dos idiomas autóctones sul-americanos, sobretudo no que diz respeito às relações entre língua e cosmologia dos povos ameríndios.

A língua Bakairi possui duas variedades: o Bakairi de Santana e o Bakairi de Paranatinga e há diferença entre estas, ao menos do ponto de vista fonológico, conforme a tese de Souza (1994). Contudo, podese observar diferenças internas como as relativas a grupamentos familiares extensos, similares a clãs, e a processos históricos como a saída dos Bakairi isolados das cabeceiras do Xingu, produzindo nas aldeias da T.I. Bakairi o reconhecimento da variedade conhecida como Bakairi Xinguano. O Bakairi de Santana pode ser considerado mais conservador, mantendo a quantidade de sílabas e a estrutura silábica conforme registrada nos trabalhos históricos sobre o Bakairi, que nas outras variantes apresenta mudança diacrônica, como se verá na próxima seção.

\section{Estudos sobre sílaba e processo de redução silábica}

Para tratar do processo de redução silábica, antes precisamos discorrer um pouco sobre a noção de sílaba. Tal noção de sílaba, de acordo com Bisol (2001, p. 13), não é recente no campo da fonologia, porém só recentemente foi atrelada à fonologia gerativa. Somente a partir dos trabalhos elaborados por Hooper (1976) e Kahn (1976), que a sílaba foi reconhecida como unidade fonológica. Com duas teorias sobre a estrutura interna da sílaba (a teoria autossegmental e a teoria métrica da sílaba), foi possível a realização de estudos silábicos. A teoria autossegmental (KAHN, 1976) presume camadas independentes, representadas pelas sílabas (que estão indicadas pela letra grega $\sigma$ ) e onde estão ligados os segmentos, como no exemplo abaixo explicitado por Bisol:

A teoria autossegmental (KAHN, 1976) presume camadas independentes, representadas pelas sílabas (que estão indicadas pela letra grega $\sigma$ ) e onde estão ligados os segmentos, como no exemplo abaixo explicitado por Bisol:o

(1)

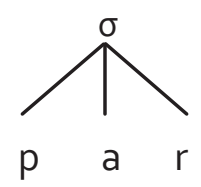

A segunda teoria justifica que as sílabas são estruturadas conforme o exemplo (2), de acordo com Selkirk (1982), com base em teses elaboradas anteriormente por Pike (1947) e Fudge (1969): 
(2)

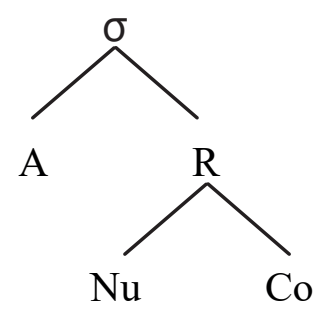

Nesta teoria, "uma sílaba consiste em um ataque $(A)$ e uma rima $(R)$; a rima, por sua vez, consiste em um núcleo (Nu) e em uma coda (Co) (Bisol, 2001, p. 92). Nota-se que as duas teorias fazem observações diferentes acerca da estrutura interna da sílaba. A primeira teoria explicita que somente a sílaba como um todo pode ser citada pelas regras fonológicas, ou seja, não há uma divisão interna mais elaborada, pois, todos os segmentos estão relacionados a um só elemento, que é a própria sílaba em si. Já a segunda teoria expõe que tal relacionamento (sílaba e os segmentos) é mais profundo e detalhado, pois, de acordo com o exemplo (2), a consoante do núcleo da sílaba e a coda da mesma constituem a rima da sílaba, enquanto o ataque é uma parte independente.

Tais teorias apresentadas acima contribuíram para a organização do estudo da sílaba em diferentes línguas e foram necessárias para mostrar o quanto é importante o estudo da sílaba, componente linguístico que apresenta toda uma característica minuciosa. Assim, constituem o molde silábico, que é o modelo de silaba que cada língua possui. As línguas distinguem-se no número de segmentos disponíveis em cada molde silábico. Tal molde permite o número máximo e mínimo de elementos numa sílaba de determinada língua.

Na língua portuguesa não há, segundo Bisol (2001, p. 98), um acordo em relação ao número máximo de elementos permitidos em uma sílaba, porém as estruturas silábicas permitidas são5:

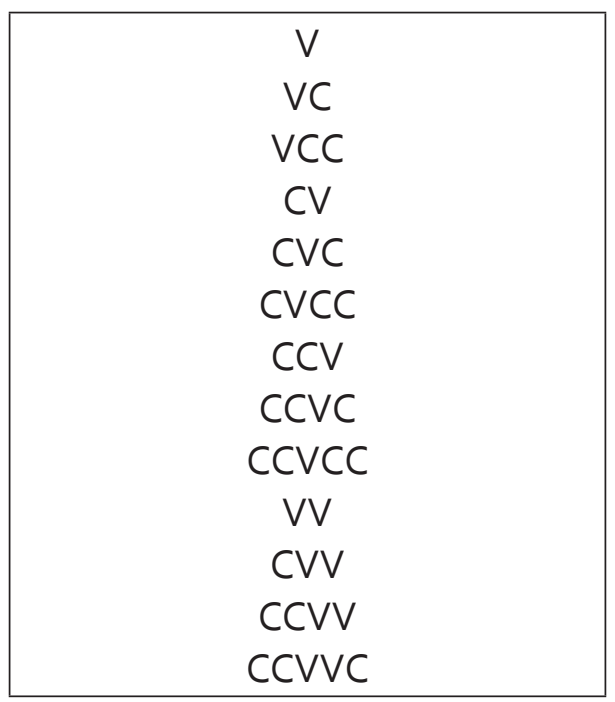

Fonte: Bisol, 2001.

Temos na ressilabificação, segundo Bisol (2001, p. 118), um processo que, juntamente com três fenômenos distintos: a elisão, a ditongação e a degeminação, analisa a ocorrência vocálica e suas alterações nas sílabas e seus ajustes na fala e explica melhor como ocorre o processo de redução silábica em certa língua. 
$\diamond$ A elisão afeta a vogal baixa da sílaba e ocorre quando a vogal seguinte for posterior, sendo aplicada somente na fronteira entre as palavras (coda da primeira palavra e ataque da segunda) e não no interior destas. E ocorre somente se as duas vogais (a vogal da coda e a vogal do ataque) forem átonas.

$\diamond$ A ditongação não é restrita somente a fronteira das palavras, podendo ocorrer também em seu interior, desde que uma das vogais presentes seja alta (segmental) e átona (rítmica).

$\diamond$ A degeminação acontece quando as duas vogais que se encontram são semelhantes (nas fronteiras das palavras ou no interior de cada palavra), desde que a segunda vogal não tenha acento.

\section{A redução silábica em Bakairi}

Historicamente, registra-se na língua Bakairi um processo de queda de segmento intervocálico, provavelmente uma consoante marcada pelo traço [+ coronal]. Ao comparar os dados atuais da língua, registrados por Souza (em vários trabalhos), com os dados que se têm em Von den Steinen (1884) e Capistrano de Abreu (1885), observa-se que no Bakairi do século XIX, os autores não registravam nenhuma vogal com traço de nasalidade. Entretanto, nos dados atuais, é grande a incidência de vogais nasalizadas.

Em termos fonológicos, o resultado do processo de queda do segmento consonantal deu lugar a sílabas pesadas, no interior e no final da palavra, o que demanda uma análise da estrutura silábica atual. Este mesmo processo atingiu a consoante nasal alveolar /n/ em vários morfemas. São fatos que reconfiguram a morfologia da língua. Como procedimento de análise, buscamos comparar dados atuais coletados por Souza (durante os anos de 1984 e 1990) e dados de pesquisa de campo, realizada em março de 2013, com os dados registrados em Von den Steinen (1892) e em Capistrano de Abreu (1895).

Ainda como procedimento analítico, enfocaremos as vogais nasalizadas em dois grupos: (I) as que decorrem de um processo diacrônico de redução silábica, resultando no processo de ressilabificação e (II) as que são decorrentes desse mesmo processo, mas que acabaram por instituir na língua uma nasalidade morfológica.

Grupo I: Nasalidade Fonética

\begin{tabular}{|c|c|c|c|}
\hline & *SÉCULO XIX & SÉCULOS XX e XXI & Tradução \\
\hline 1 & ayaitino & [a'yajtĩõ] & 'velho' \\
\hline 2 & anagido & $\left[\tilde{a}^{\prime n}\right.$ gid $\left.)\right]$ & 'animal' \\
\hline 3 & anahi & ['ãnzi] & 'milho' \\
\hline 4 & ukoroto & {$\left[u^{\prime} g \partial^{n} d \supset\right]$} & 'homem' \\
\hline 5 & iramuto & [yã'mũndo] & 'criança' \\
\hline 6 & pakunera & [pakwera] & Rio das pombas \\
\hline 7 & âmâremo & [əməmว] & $3 p$ plural \\
\hline
\end{tabular}


As evidências da redução silábica também podem ser observadas no plano sincrônico quando se compara a fala de anciãos, como o xamã Vicente (falecido, mas que contava com 90 anos à época da pesquisa) com os dados de Bakairi mais jovens.

\begin{tabular}{|l|l|l|l|}
\hline & Informante I (9o anos) & Informante 2 (30 anos) & Tradução \\
\hline 8 & noroko & [nokJ] & 'matrichã' \\
\hline
\end{tabular}

Assim, nos dados do grupo I (1-8), observa-se que houve queda do segmento $\mathbf{r}$ e $\mathbf{n}$ entre vogais, resultando, hoje em dia, em vogais nasalizadas, não registradas nem por Von den Steinen, nem por Capistrano de Abreu. A interpretação do segmento grafado como r, por sua vez, leva à conclusão de que, na maior parte dos casos, se trata de um flap nasal. Essa possibilidade (a de ser um flap nasal) é reforçada por duas evidências. (1) O processo de redução silábica só atingiu palavras com mais de duas sílabas.

Comparando duas dessas palavras, registra-se, hoje em dia, a ocorrência do flap nasal como, por exemplo, em:

\begin{tabular}{|c|c|c|c|}
\hline 9 & kxana & [kãrã] & 'peixe' \\
\hline 10 & ono & [กัว] & 'terra' \\
\hline
\end{tabular}

(2) A outra evidência é encontrada, por exemplo, numa palavra como [ $\left.u^{\prime} g{ }^{n} d \supset\right]$, proveniente de 'ukoroto', cuja nasalidade, hoje em dia, só se explica se for aventado que o segmento r, seria marcado com traço nasal. No Bakairi, conforme visto, o primeiro passo da redução silábica é a consoante. Os segmentos consonantais atingidos, no entanto, são reduzidos. Não abarca as obstruintes, mas majoritariamente os seguintes segmentos soantes coronais: tap oral, tap nasal e nasal coronal. $\mathrm{O}$ tap nasal é um segmento ausente tanto na descrição sincrônica da língua quanto na reconstrução do Pré-Bakairi feitas por Meira (2005), lapso que cria inúmeras situações em que a origem da nasalidade teria que residir nas vogais, fenômeno não atestado para o Bakairi. A lacuna também torna impossível

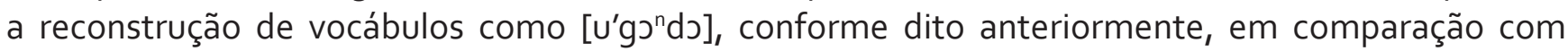
registros históricos onde apenas a versão não-nasalizada do tap está presente ${ }^{1}$. O vocábulo rende um dos inúmeros momentos de franca especulação e nenhuma economia em termos de explicação linguística do texto de Meira (2005, p. 267) sobre o Pré-Bakairi:

A second problem [com a palavra u'gondə] is the presence of nasality in the Eastern Bakairi
form: none of the other forms - in fact, no cognate form from any other Cariban language-has
a nasal vowel or consonant. The only suggestion that comes to mind is to suppose that the final
do is an old number suffix (cf., e.g., the forms karaiwa 'foreigner' and karaiwa-do 'foreigners')
that lexicalized as part of the stem, a fairly frequent phenomenon in Cariban languages.
Cognates of this suffix from other Cariban languages do have a nasal consonant (e.g., Tiriyó
ton tomo, Wayana tom nomo), which could presumably have yielded *to in (Pre-)Bakairi.
In a form like *Vgurotõ, the nasality might have changed syllables to *Vgurõto (perhaps via
an intermediate assimilated form *Vgurõtõ), which would then develop into Eastern Bakairi
uguõdo. This is a plausible story; but, in the absence of further confirming evidence, it remains
speculative.

1. Em Von den Steinen, os vocábulos que hoje apresentam o tap nasal são registrados ora como coronal nasal ora como tap oral. Em Capistrano de Abreu o reconhecimento de que o segmento em questão envolvia propriedades da nasal e da líquida está no duplo registro de palavras como [kãrã] peixe, grafada pelo autor cearense como kara e kana. 
Tais especulações tanto carecem de evidência empírica como demonstram o desconhecimento do autor de fatos básicos sobre o Bakairi. Em primeiro lugar, o idioma registra a existência do sufixo [ modo], que atua como coletivizador nominal (e não exatamente plural), não se fazendo, portanto, necessário o apelo para a postulação de um morfema [ tomo] reconstruído sem qualquer atestação na língua para dar conta da nasalização de um único segmento. O arrazoado também não se mostra plausível por conta das características do espraiamento da nasalidade do Bakairi, de adjacência imediata à esquerda da consoante nasal, fenômeno que estaria bloqueado pela oclusiva [t]. O morfema [ modo] possui inclusive a ordem silábica inversa à dos cognatos selecionados por Meira, e registra-se ainda co-ocorrência dele com o mesmo sufixo que o autor identifica como plural, mas que possuí função muito mais complexa na língua, abrangendo aspectos funcionais e semânticos (cf: BONFIM, 2018). Tal sufixo é extremamente produtivo, podendo, por exemplo, ser afixado à palavra de estrutura similar e pertencente ao mesmo campo semântico de "homem":

(11.a) peko-do (mulher comum)

(11.b) peko-baym (hiper-mulher, mulher mítica)

(11.c) peko-do-mõdo (mulherada)

Devido ao fato que a redução silábica em Bakairi ser diacrônica, e não sincrônica (devido a fenômenos como afixação), e ocorrida ao longo dos últimos cem anos, ou seja, após os registros de Von den Steinen e Capistrano de Abreu, encontra-se ainda variação sociolinguística baseada na faixa etária e comunidades de fala mais conservadoras (como o Bakairi de Santana), com o registro de formas curtas e longas de acordo com a geração, conforme discussão do dado 6. A queda consonantal, contudo, apresenta aspectos morfofonêmicos como mostra o quadro abaixo.

Grupo II: Nasalidade Morfológica

\begin{tabular}{|c|c|c|c|}
\hline & SÉCULO XIX & SÉCULOS XX-XXI & Tradução \\
\hline 12 & $\begin{array}{l}\text { ka - } \mathbf{n} \text { - utu - ba 1su.zob. } \\
\text { conhecer.neg. }\end{array}$ & $\begin{array}{l}\text { [kã - u'tu - ba] } \\
\text { 1su. zob.conhecer.neg. }\end{array}$ & 'Eu não o conheço' \\
\hline 13 & $\begin{array}{l}\text { ma - n - utu - ba 2su.3ob. } \\
\text { conhecer.neg. }\end{array}$ & $\begin{array}{l}\text { [mã - u'tu - ba] 2su.3ob. } \\
\text { conhecer.neg. }\end{array}$ & 'Você não o conhece' \\
\hline 14 & $\begin{array}{l}\text { i - n - utu - ba 3su.zob. } \\
\text { conhecer.neg }\end{array}$ & $\begin{array}{l}\text { [ỹ - u'tu - ba] 3su.zob. } \\
\text { conhecer.neg }\end{array}$ & 'Ele não o conhece' \\
\hline 15 & $\begin{array}{l}\text { Kxa-n-eyatu-agi 1su.3ob. } \\
\text { narrar.passado }\end{array}$ & $\begin{array}{l}\text { [kã - eyatu -'agi] 1su.3ob. } \\
\text { narrar.passado }\end{array}$ & 'Eu narrei' (algo) \\
\hline 16 & $\begin{array}{l}\text { ma - } \mathbf{n} \text { - eyatu - agi } \\
\text { 2.su.zob.narrar.pass. }\end{array}$ & $\begin{array}{l}\text { [mã - eyatu - 'agi] 2.su.3ob. } \\
\text { narrar.passado }\end{array}$ & 'Você narrou' (algo) \\
\hline 17 & $\begin{array}{l}\mathrm{i}-\mathrm{n} \text { - eyatu - agi } \\
\text { 3su.3obj.narrar.pass. }\end{array}$ & $\begin{array}{l}\text { [ỹ - eyatu - 'agi] 3s.3ob. } \\
\text { narrar.passado }\end{array}$ & 'Ele narrou' (algo) \\
\hline 18 & $\begin{array}{l}\text { eyatu - ne } \\
\text { Contar -nominalizador }\end{array}$ & $\begin{array}{l}\text { [eya'tũj] } \\
\text { Contar-nominalizador }\end{array}$ & 'Contador de história' \\
\hline 19 & $\begin{array}{l}\text { tilaze - ne } \\
\text { Secar -nominalizador }\end{array}$ & $\begin{array}{l}\text { [tila'zẽj] } \\
\text { Secar -nominalizador }\end{array}$ & 'Magro' (adjetivo) \\
\hline 20 & $\begin{array}{l}\text { tadige - ne } \\
\text { Gordura - nom. }\end{array}$ & $\begin{array}{l}\text { [tadigẽj] } \\
\text { Gordura-nominalizador }\end{array}$ & 'Gordo' (adjetivo) \\
\hline
\end{tabular}


Nos dados do grupo II, se assinala a queda do - n -, morfema de $3^{\text {a }}$. pessoa-objeto e a queda do -n- no formativo -ne, nominalizador. No Bakairi, conforme a tese de Souza (1995), o caso estrutural absolutivo se manifesta na marca de objeto, obedecendo ao alinhamento SOV/OV atribuidor de caso na língua, o que implica no estatuto morfológico da nasalidade assimilada pela vogal da nasal apagada.

É importante destacar o papel morfológico do sistema de traços do Bakairi, que não se limita a nasalidade, mas concorre para outros fenômenos importantes da língua. Devido à organização fonológica da língua obedecer a alternância de fonemas surdos e sonoros, o traço [+voz] atua distintivamente apenas dentro de campos semânticos, conforme assinala Souza (1995, p.46). Devese destacar, contudo, que tais campos em muitos casos são culturalmente circunscritos, seguindo a lógica do pensamento indígena, como nos dados abaixo:

(21) nykeagi (ele morreu)

(22) nygeaki (ele dormiu)

Para os Bakairi, quando a pessoa dorme, a alma (kahadobyre) sai do corpo, voltando ao despertar. Mas ao se dormir, por exemplo, com sede, a alma pode se perder em busca de água e não voltar mais. A pessoa permanece então permanentemente dormindo como na morte. A mínima diferença entre os dois processos vitais fica marcada pela alternância surdo/sonoro, que por sua vez alterna o ponto de partida da harmonia mais ampla da língua motivando o registro dos alomorfes [ aki] e [ agi] para passado recente. Assim, como o traço [-voz] é default, pode-se postular [+voz] como morfema alternante que atua para distinções no interior de campos semânticos, mantendo-se a previsão geral da impossibilidade de indeterminação dos fonemas da língua em decorrência da harmonia consonantal (SOUZA, 1995).

\section{5. À Guisa de Conclusão}

A partir da discussão sugerida pelos quadros acima, podemos inferir que:

$\diamond$ A queda do segmento [nasal] [+coronal] intervocálico atingiu formativos (cf: Grupo II) e não formativos (cf: Grupo I), condicionada pelo processo de redução silábica, comum às línguas da família Karib, porém ocorrida de forma diferenciada na língua Bakairi, por não haver reduções silábicas sincrônicas, como ocorre em Ikpeng devido a processos de afixação (Alves 2013) e condicionadas por questões, por exemplo, de natureza prosódica, conforme a descrição geral fornecida por Gildea (1995).

$\diamond$ A língua Bakairi apresenta dois tipos de nasalidade - uma fonética, outra morfológica.

$\diamond$ É notório um processo de redução silábica no Bakairi e uma restruturação da língua de acordo com os séculos estudados. Nos registros do século XIX foram observados, apenas, dois padrões silábicos: $\mathrm{V}$ e $\mathrm{CV}^{2}$. Fato que nos leva às seguintes observações:

$\diamond$ Até o presente século, há a manutenção desses padrões e a não previsão de coda na língua;

$\diamond$ A ausência do segmento nasal em coda não explicaria, porém, a origem da nasalidade fonética, o que leva a postular, para o Bakairi, uma série de oclusivas pré-nasalizadas - [ ${ }^{\mathrm{m}} \mathrm{p}_{i}$ $\left.{ }^{m} b ;{ }^{n} t ;{ }^{n} k ;{ }^{n} g\right]$ e uma série de fricativas pré-nasalizadas $-\left[{ }^{n} s_{i}{ }^{n} z_{i}{ }^{n} ;{ }^{n} 3\right] ;$

2. As siglas $\vee$ e $C$, descritas a partir do esquema correspondem a: $\vee$ (vogal) e $C$ (consoante). 
$\checkmark$ A melhor representação da sílaba em Bakairi parece ser aquela que prevêum relacionamento hierárquico entre os constituintes da sílaba (SELKIRK, 1982 e outros), fazendo afirmar, portanto, que a queda dos segmentos atinge a rima das palavras com mais de três sílabas. Essa conclusão se baseia em dois princípios: o Princípio do Contorno Obrigatório em Bakairi, que não prevê vogais geminadas ou longas (como acontece com outras línguas da família Karib) e o Princípio de Economia que atua na preservação do sistema da língua, que não previa sílaba com coda.

Embora dentro do quadro das línguas Karib, o Bakairi apresente o movimento de redução silábica, a variação em Bakairi se deu tanto no nível intralinguístico, com a redução silábica, quanto no nível interlinguístico, neste caso, diferenciando-se das línguas da mesma família por não desenvolver sílabas com coda, nem ataques complexos, em prol da manutenção do padrão $(C) \vee(\forall)$, tendo este padrão silábico a seguinte configuração:

(3)

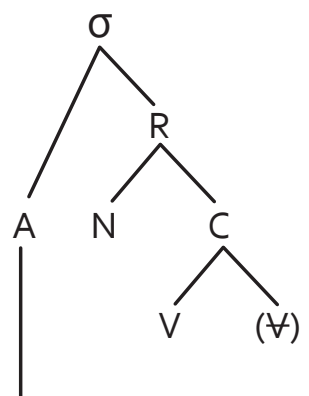

(C)

Assim, o estudo da redução silábica no Bakairi se mostra importante dentro dos esforços mais amplos de classificação interna da Família Karib por se tratar de fenômeno abrangente atinge todas as línguas do agrupamento genético, porém de maneira diferenciada. Com a ocorrência do fenômeno apresentando características próprias, as formas encontradas no Bakairi atual são importantes para a reconstrução do Proto-Karib diante da regularidade na queda de consoantes específicas sem alterar o padrão silábico e preservando constituintes atingidos pelas demais formas de redução silábica em outras línguas da família.

\section{Referências}

ALVES, Ana Carolina Ferreira. Aspectos do Sistema Fonológico Arara (Caribe). Boletim do Museu Paraense Emílio Goeldi (Ciâncias Humanas), Belém, v. 8, n. 2, p. 265-277, maio-ago. 2013.

BISOL, Leda (Org.). Introdução a estudos de fonologia do português brasileiro. 3 ed. Porto Alegre: EDIPUCRS, 2001.

BONFIM, Evandro de Sousa. Como o Narrador e a Língua Estruturam o Mito: as Interferências no Conto Bakairi -A Onça e o Tamanduá. Revista del Museo de Antropologia, v. 11, p. 17-24, 2018.

CALLOU, Dinah; LEITE, Yonne. Iniciação à fonética e à fonologia. 11 ed. Rio de Janeiro: Jorge Zahar, 2009.

CAPISTRANO DE ABREU, J.C. Os Bacaerys. Revista Brasileira. 10 anos, t. III e t. IV, Rio de Janeiro, 1985. 
GILDEA, Spike. A comparative description of syllable reduction in the Cariban language family. International Journal of American Linguistics, v. 61, p. 62-102, 1995.

GILDEA, Spike; PAYNE, Doris. Is Greenberg's Macro-Carib viable? Boletim do Museu Paraense Emílio Goeldi (Ciências Humanas), v.2, n. 2, p. 19-72, 2007.

MATTEI-MULLER, Marie-Claude. La reduccion silabica en Panare. Amerindia, n. 6, pp. 59-84, 1981.

MEIRA, Sérgio. Reconstructing Pre-Bakairi Segmental Phonology. Anthropological Linguistics, v. 47, n. 3, p. 261-291, 2005.

MEIRA, Sérgio; FRANCHETTO, Bruna. The southern Cariban languages and the Cariban family. International Journal of American Linguistics, v.71, p. 127-192, 2005.

NESPOR, M.; VOGEL, I. Prosodic phonology. Holland: Foris Publications, 1986

PEIXOTO, B. A. S.; ROSA, R.P.S. Dois paradigmas verbais em Bakairi: o debate entre von den Steinen e Capistrano de Abreu. 2014. Apresentação na Jornada de Iniciação Científica - UFRJ.

ROSA, Rodrigo Pereira da Silva. Alguns aspectos gramaticais do Bakairi. 2017. Monografia, Universidade Federal do Rio de Janeiro, 2017.

SOUZA, Tânia Clemente de. O Traço Sonoro em Bakairi. In WETZELS, L. (Org). Estudos Fonológicos das Línguas Indígenas Brasileiras. Rio de Janeiro: Editora da UFRJ, pp. 29-52, 1995.

SOUZA, Tânia Clemente de. Discurso e Oralidade: um Estudo em Língua Indígena. Niterói: publicações do MCII/UFF, 1999 .

SOUZA, Tânia Clemente de. Alguns aspectos da ergatividade em Bakairi. Estudos da língua(gem), v. 4, n. 2, pp. 137-152, 2006.

VON DEN STEINEN, K. Die Bakairi Sprache. Leipzig, 1982. 